\title{
EL USO DE LAS TICS EN LA ENSEÑANZA DEL PROYECTO. UNA EXPERIENCIA DOCENTE
}

Artículo de Reflexión - Recibido 15 de Agosto de 2015 - Aceptado 22 de Noviembre de 2015

\author{
Fernando Speranza ${ }^{1}$
}

Universidad de Buenos Aires. Buenos Aires, Argentina. info@catedrasperanza.com.ar

\section{Marcela Castressana ${ }^{1}$}

Universidad de Buenos Aires. Buenos Aires, Argentina. info@catedrasperanza.com.ar

\section{Horacio Garaventa}

Universidad de Buenos Aires. Buenos Aires, Argentina. info@catedrasperanza.com.ar

Roberto J. Londoño²

Universidad de los Andes. Bogotá, Colombia. rlondono@uniandes.edu.co

Para citar este artículo / to reference this article:

Speranza, F., Castressana, M., Garaventa, H. y Londoño, R. (2016). El uso de las TICs en la enseñanza del proyecto. Una experiencia docente. Módulo Arquitectura CUC, Vol.16 N¹, 73-86.

\section{Resumen}

El uso de la Tecnología de las Comunicaciones empieza a ser un hecho presente en los procesos de enseñanza y aprendizaje de la arquitectura y del proyecto de manera cada vez más evidente. El trabajo que se presenta intenta responder a la pregunta por el uso de las TICs en la enseñanza del proyecto y lo hace desde la experiencia concreta que tuvo lugar entre tres escuelas de arquitectura: La FADU, en Buenos Aires, La Universidad Nacional y la Universidad de los Andes en Colombia. La experiencia en formato de Workshop indagó en diferentes posibilidades en el uso de la representación, la comunicación y el trabajo colaborativo.

\section{Palabras clave}

Tecnología, comunicaciones, Tics, enseñanza, aprendizaje. 


\section{THE USE OF ICT IN TEACHING THE PROJECT. A TEACHING EXPERIENCE}

\section{Abstract}

The use of Information and Communications Technology nowadays is becoming a relevant fact in the teaching and learning processes of architecture and projects. This work is aimed to response the question of the use of ICT in the teaching of projects, the mentioned response comes from the actual experience that was carried out between three colleges of architecture; these institutions were FADU, in Buenos Aires, the National University and De los Andes university in Colombia. The experience in Workshop format has researched as well different possibilities in the use of representation as communication and collaborative work.

\section{Keywords}

Technology, communications, Tics, teaching, learning. 


\section{Introducción}

El trabajo que se presenta corresponde al relato y a la reflexión sobre una experiencia didáctica basada en el uso de las TICs aplicadas en un ejercicio proyectual donde se quiso poner en juego la utilización de la tecnología para habilitar un proceso de diseño compartido así como la negociación entre miembros de comunidades académicas distintas. Con esto se buscó además trascender el uso generalizado de tecnología como medio para la elaboración tradicional de planos o modelos y valerse de los medios de comunicación para habilitar la circulación de ideas ${ }^{3}$.

La idea de un intercambio académico de esta naturaleza surge desde la Cátedra Speranza del Ciclo Básico Universitario en la Facultad de Arquitectura Diseño y Urbanismo de la Universidad de Buenos Aires. $\mathrm{Ha}$ contado con versiones anteriores entre la Cátedra Speranza, la Universidad Politécnica de Cataluña y la Universidad de Lile; antecedentes en los que se han puesto a prueba variaciones sobre el esquema general en sus métodos e instrumentos enfocados siempre en

3 La crítica al uso de los medios como emuladores de la representación análoga ha sido una constante en la reflexión sobre las TICs en la formación de los arquitectos. Velandia (2009) cumplir objetivos didácticos e investigativos ${ }^{4}$.

La experiencia, en formato de workshop se basó en la capacidad que ofrecen los medios para la comunicación en tiempo sincrónico y diacrónico como recursos para cumplir los objetivos pedagógicos propuestos. Se involucraron simultáneamente tres comunidades académicas distintas que durante cerca de seis semanas estuvieron trabajando de forma coordinada bajo unas premisas comunes en las que se rompe la secuencia del proceso tradicional, la noción de la autoría y las variables de uso y lugar, dando así lugar al calificativo de "ficciones espaciales".

Los objetivos del ws siguieron dos caminos paralelos: El primero (centrado en los docentes) se propuso como una indagación didáctica basada en la experimentación y exploración de modos de trabajo que suprimieran la distancia con base en las TICs y el desarrollo de un proceso proyectual en el que se verificaran conocimientos construidos entre docentes y estudiantes de diversos ámbitos académicos vincu-

4 Ver Speranza (2014). 
lados al primer año de formación. ${ }^{5}$ El segundo (centrado en los estudiantes) estuvo referido al ejercicio en sí mismo y se basó en la aproximación al proyecto desde una narrativa proyectual fundamentada en la co-producción y el emplazamiento de objetos habitables (llamados objeto - espacio) simples concebidos colaborativamente.

\section{Relato}

El ws "Ficciones Espaciales" que se realizó durante Octubre y parte del mes de Noviembre de 2014 reunió cerca de trescientos (300) estudiantes y dieciocho (18) docentes, todos, inscritos en cursos del primer año de carrera en las siguientes escuelas de arquitectura:

1. Curso Introducción al pensamiento proyectual, Cátedra Speranza, del Ciclo Básico común de la FADU UBA (FADU). Este se define como un curso introductorio, nivelatorio y propedéutico dirigido a estudiantes de las distintas carreras: Arquitectura, Diseño Gráfico, Diseño Industrial, Diseño de Indumentaria, Diseño

5 La convicción detrás de esta intención se basa en la posibilidad de incluir la investigación en las asignaturas de diseño, tanto a nivel del curso en sí mismo como a nivel de los estudiantes de modo que desde la práctica
Textil, Diseño en Imagen y Sonido y Diseño del Paisaje ${ }^{6}$. Cantidad de estudiantes: 130 (aprox.).

2. Curso Proyecto 1 de la Escuela de Arquitectura de la Universidad Nacional de Colombia (sede Bogotá) (UN). Tiene como objetivo introducir al estudiante en los conceptos básicos de la composición y del manejo del espacio arquitectónico, desde la experiencia individual a través de los elementos y relaciones que componen el espacio arquitectónico, así como los factores y procedimientos que intervienen en su configuración. (Cantidad de estudiantes: 80 aprox.).

3. Curso, Taller de Composición 2, del Ciclo Básico del programa de Arquitectura en la Universidad de los Andes (UA). Se ubica en el segundo semestre de la carrera y antecede el paso al Ciclo Formativo. En tanto curso introductorio, aborda el problema de la arquitectura desde los fundamentos disciplinares y apuesta por una aproximación pedagógica basada en las competencias. (Cantidad de estudiantes: 90 aprox.).

6 Las carreras denominadas "proyectuales" en la Universidad de Buenos Aires, se agrupan en un curso dictado anualmente en el que se imparten contenidos centrados en los problemas del diseño que serán especializados en las siete disciplinas que conforman la facultad. 
Se trató por tanto de poner en relación tres ámbitos académicos diferentes en los que, no obstante, se mantuvo en común la preocupación por explorar los diversos caminos que tiene el proyecto en tanto proceso creativo capaz de vincular el pensamiento, la imaginación, la forma y el habitar como aspectos centrales en la formación básica7. Proceso que dio nombre al ws: "Ficciones Espaciales", en tanto se buscó alterar permanentemente el paradigma metodológico del proyecto basado en la secuencialidad, en la autoría única y en la referencia a un programa y unos lugares determinados de antemano. Así, mediante la ficción, se quiso privilegiar la experimentación y la búsqueda sobre las certezas en las que se basan este tipo de ejercicios.

El ws intentó por tanto plantear en una experiencia pedagógica que potenciara la creatividad mediante el cuestionamiento y la alteración de parámetros fijos. Así, en contra de la convención se quiso promover la negociación entre pares, sobre la premisa del trabajo colaborativo, la co-autoría y una narración proyectual que sucediera en ámbitos claramente diferenciados.

7 El diseño curricular a nivel de primer año presenta siempre un dilema que en palabras de Peggy Deamer, nunca logra un programa "ideal" y en cambo sí, tentativas que pueden ser "correctas". Deamer (2005).
De este modo se asumió una posición crítica que otorgara valor al proceso creativo basado en la ambigüedad entre la interpretación y lo verosímil.

Para lograr dar cumplimiento a los objetivos, tanto de la indagación didáctica (a nivel de los docentes) como del ejercicio en sí mismo (a nivel de los estudiantes), se propuso seguir tres fases que tuvieron lugar a lo largo de las seis semanas que duró el ejercicio. Dichas fases estuvieron marcadas por tres encuentros virtuales (videoconferencias), uno al inicio, en el que el profesor Fernando Speranza explicó el sentido del ws; un segundo en el que se establecieron los términos del intercambio y el tercero, de cierre, donde algunos de los estudiantes expusieron sus trabajos.

La primera fase (semana 1 a 3), se concentró en la producción de un objeto - espacio que surgiera de un detonante proveniente de otro lenguaje, en un proceso desvinculado de cualquier relación con un lugar o con un programa determinado. ${ }^{8}$ Se insistió de todas maneras, en que debía ser un objeto transitable, es decir habitable como condición esencial y

8 Se explicará adelante que se entiende por objetoespacio así como las diferentes maneras en que cada grupo asumió - desde otro lengaje- el inicio del trabajo. 
Tabla 1

Cronograma de las seis sesiones en las que se desarrolló el Workshop Ficciones espaciales.

\begin{tabular}{|c|c|c|c|c|}
\hline & & ACTIVIDAD & Producto & Recurso Tic. \\
\hline \multirow{4}{*}{ 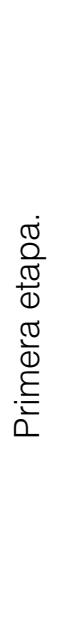 } & 1 & $\begin{array}{l}\text { CLASE: Producción imágenes detonadoras. } \\
\text { Videoconferencia, presentación del ejercicio. }\end{array}$ & & $\begin{array}{l}\text { Video conferencia } \\
\text { 1. Introducción } \\
\text { a cargo del } \\
\text { profesor Fernando } \\
\text { Speranza } \\
\text { CBC-FADU }\end{array}$ \\
\hline & & $\begin{array}{l}\text { TAREA 1:Producir una postal y subir al grupo de fb. } \\
\text { 2. Producir dibujos y primera maqueta del objeto } 3 \text {. } \\
\text { Anotaciones en la bitácora. . }\end{array}$ & & $\begin{array}{l}\text { Vídeo } 1 . \\
\text { Presentación del } \\
\text { workshop. }\end{array}$ \\
\hline & & $\begin{array}{l}\text { CLASE: Análisis del objeto producido desde tres modos } \\
\text { constructivos: lineal, planar o volumétrico. }\end{array}$ & & $\begin{array}{l}\text { Vídeo 2. ¿Qué es } \\
\text { un objeto-espacio? }\end{array}$ \\
\hline & 2 & $\begin{array}{l}\text { TAREA: 1. Modificar maqueta a partir de los comentarios } \\
\text { hechos en clase. 2, Producir, imprimir panel } 1 \text { con las } \\
\text { imagens de la maqueta corregida. 3. Preparar envío del } \\
\text { panel 4. Anotaciones en la bitácora }\end{array}$ & & \\
\hline
\end{tabular}

cuyas premisas técnicas podían estar fundamentadas en la construcción mediante elementos lineales, planares o macizos.

La segunda fase se refirió al proceso de síntesis, esto es la representación y la presentación del objeto - espacio como condición para el intercambio entre los estudiantes de los tres ámbitos académicos enunciados arriba. Esto supuso hacer un esfuerzo por logar la mayor legibilidad de la idea y su proceso de manera que pudiera ser leído e interpretado con claridad por un par en otro grupo. ${ }^{9}$

La tercera se basó en la interpretación del objeto recibido y en la operación de localización y emplazamiento en algún lugar determinado de la ciudad. Esto, en un diálogo entre el

9 Es importante aclarar que por razones de tiempo, no se esperaba que los estudiantes lograran una propuesta totalmente definida. Se trataba en cualquier caso de objetos en los que existía un amplio margen para el posterior desarrollo en asuntos formales, funcionales y técnicos. 
Cont...

\begin{tabular}{|c|c|c|c|}
\hline \multirow{3}{*}{ 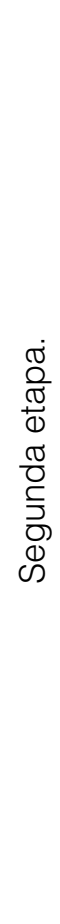 } & 3 & $\begin{array}{l}\text { CLASE: Envío del panel 1. Iniciar interpretación } \\
\text { del objeto recibido a partir de la mirada sintáctica, } \\
\text { semantica y fenomenológica. Anotaciones en la bitácora. } \\
\text { Videoconferencia, Interpretación y emplazamiento. } \\
\text { TAREA: 1. Terminar maqueta del objeto recibido. } 2 \text {. } \\
\text { Selección de un punto en el lugar de emplazamiento } \\
\text { y tomar fotos del mismo. 3. Producir memoria con las } \\
\text { consideraciones del lugar. 4. Anotaciones en la bitácora. }\end{array}$ & $\begin{array}{l}\text { Video conferencia } \\
\text { 2. Términos para } \\
\text { el intercambio de } \\
\text { paneles. } \\
\text { Vídeo 3. Tres } \\
\text { formas de ver: } \\
\text { fenomenología, } \\
\text { semántica y } \\
\text { sintaxis. }\end{array}$ \\
\hline & 4 & $\begin{array}{l}\text { CLASE: Presentación de los lugares y primera propuesta } \\
\text { de emplazamiento y de programa. } \\
\text { TAREA. 1. Producir e imprimir panel } 2 \text { con propuesta } \\
\text { de emplazamiento. 2. Ajuste del objeto y asignación del } \\
\text { programa. 3. Anotaciones en la bitácora }\end{array}$ & $\begin{array}{l}\text { Vídeo 4: Formas } \\
\text { de emplazamiento. }\end{array}$ \\
\hline & 5 & $\begin{array}{l}\text { CLASE: Verificación del emplazamiento + programa } \\
\text { de uso + técnica constructiva de los objetos. Discusión } \\
\text { sobre los componentes, sistemas y elementos tecnicos. } \\
\text { Anotaciones en la bitácora } \\
\text { TAREA: } 1 \text {. Preparar presentación final en panel 2. } 2 \text {. } \\
\text { Presentación ppt (3 min) con el proceso 3. completar } \\
\text { Ficha de estudiante con resumen del proceso }\end{array}$ & \\
\hline 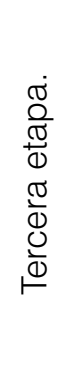 & 6 & $\begin{array}{l}\text { CLASE: Verificación del panel de envío 2. Verificación } \\
\text { de la ficha de proceso Verificación del ppt con la } \\
\text { presentación final. Videoconferencia + ENTREGA } \\
\text { FINAL y presentación de algunos trabajos en la } \\
\text { videoconferencia } \\
\text { TAREA: Preparar materiales de todo el curso para la } \\
\text { sesión final de evaluación. Se buscará responder a } \\
\text { las preguntas ¿qué aprendimos este semestre? ¿Qué } \\
\text { preguntas quedan? ¿Cómo lo aprendimos? }\end{array}$ & $\begin{array}{l}\text { Vídeo conferencia } \\
\text { 3. Presentación de } \\
\text { algunos trabajos y } \\
\text { cierre. }\end{array}$ \\
\hline
\end{tabular}

Fuente: Elaboración propia a partir de Speranza (2014)

autor del objeto y el encargado de su emplazamiento. La última sesión tuvo que ver con la evaluación del proceso y de los resultados correspondientes.
En resumen, el desarrollo supuso la producción de un objeto-espacio; este objeto-espacio debió ser sintetizado en un panel especialmente diseñado 


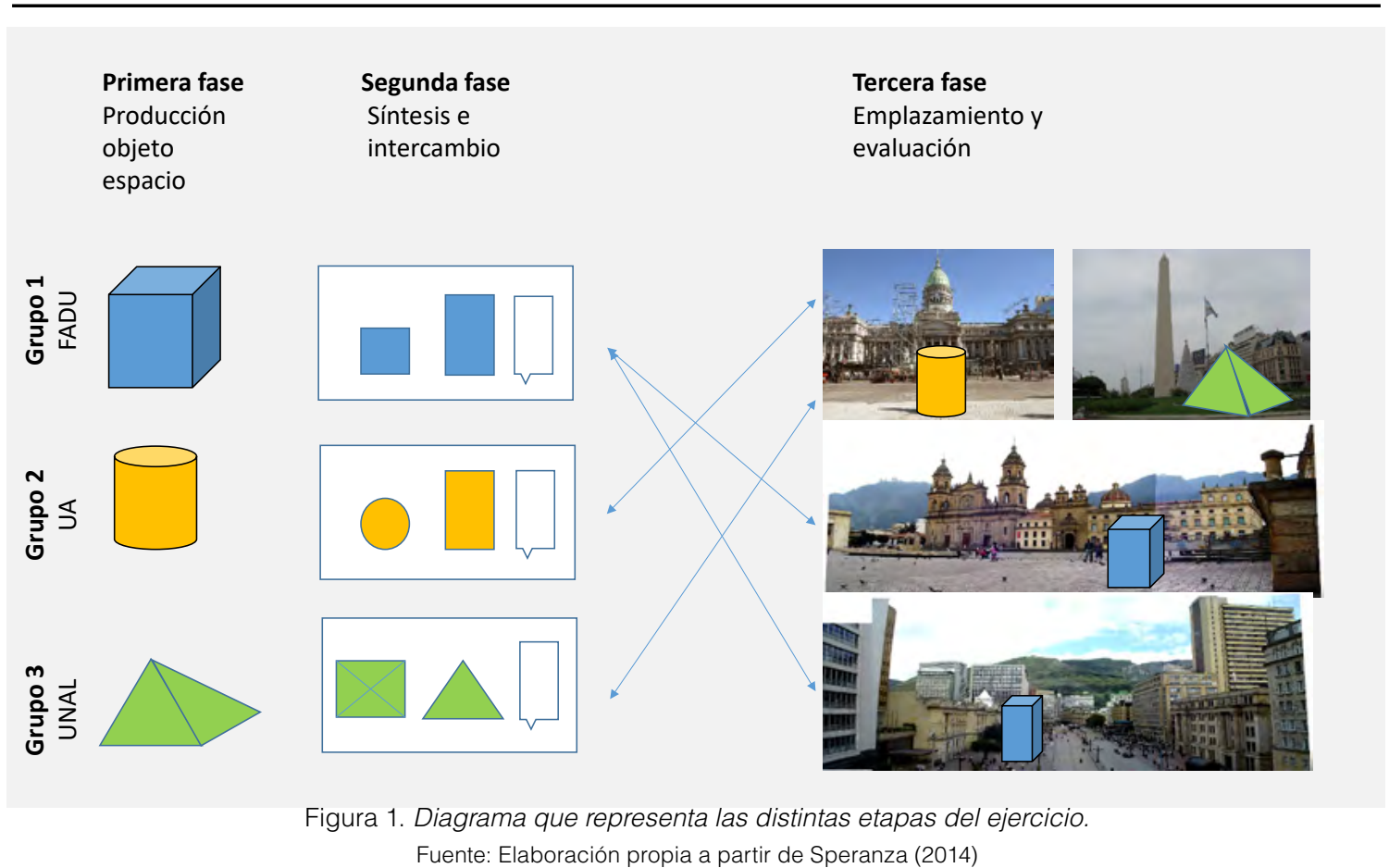

para el intercambio. Luego del intercambio, el objeto-espacio recibido debió ser interpretado y adaptado a un lugar urbano específico en el que debía conferírsele un uso que resultara adecuado tanto a la forma como al lugar de emplazamiento. Finalmente el ejercicio concluyó con la sesión del cierre y la respectiva evaluación, tanto del proceso como de los resultados.

Los recursos de comunicación empleados durante el ws fueron en principio los que existen y están disponibles de manera abierta, gratuita y los que además resultaran familiares para los estudiantes en tanto hacen parte de su vida cotidiana y pueden ser operados desde dispositivos móviles o computadoras personales.

Se propuso contar con una bitácora en la que se registrara el día a día de las distintas actividades. Esta bitácora funcionó a través de un grupo abierto de Facebook en el que tanto estudiantes como docentes pudieran hacer comentarios, subir imágenes, vídeos y hacer anuncios dirigidos al grupo o bien de manera individual ${ }^{10}$. Con esto, la bitácora manejaba un nivel de información individual así como uno grupal.

10Ver:https://www.facebook.com/groups/672677362827820/ 
Un segundo ámbito fue el portafolio. Para esto se creó un Blog en el que semanalmente se subió información seleccionada y editada de manera que pudiera tenerse un registro de la actividad del curso para que esta pudiera ser pública ${ }^{11}$. De esta manera el Blog, resume de manera cronológica los distintos módulos y actividades.

Por su parte, los estudiantes y docentes emplearon permanentemente herramientas como el correo electrónico y las aplicaciones para el envío de archivos pesados: Dropbox y Google Drive. Las teleconferencias se hicieron a través de Skype.

\section{Cuestiones problemáticas implícitas}

La realización del ws supuso una serie de cuestiones problemáticas que tocan temas de toda índole: desde aquellos que son propios del proceso creativo referido a la traducción formal de diferentes lenguajes, hasta la atención de la contingencia operativa necesarias para el funcionamiento de los tres grupos, lo que supuso, coordinar los encuentros, los formatos de intercambio y la distribución al interior de cada grupo. Se hace un recuento de las principales cuestiones que conllevó esta experiencia:

11 Ver: http://portafolioworkshopbogotabsas.blogspot.com/
¿Cómo se genera la forma inicial del objeto espacio? Las respuestas podrían sin duda ser muy diversas, y para demostrarlo se decidió que cada grupo asumiera una manera en particular. El grupo de UA, partió de la traducción de movimiento de una pareja de bailarines, lo que suponía captar el movimiento en el espacio como motivo para generar el objeto-espacio. El grupo de la UN partió del análisis de una pintura del arte abstracto que fue estudiada en términos de su composición intrínseca. $Y$, el grupo de la FADU, partió de la formulación de palabras y conceptos ordenados por categorías de manera que en su articulación permitieran producir una forma con cualidades específicas. En los tres casos, se llegó a la producción de una imagen como primer paso en la producción de una forma en tres dimensiones.

¿Cómo se materializa una imagen? El proceso de producción de la forma del objeto - espacio conlleva la materialización como condición esencial, lo que implica ciertos problemas característicos asociados a la composición de un objeto tridimensional de carácter espacial. Esto supone un importante grado de abstracción en el que la condición plana de partida debe adquirir altura, volumen y forma así como un principio técnico constructivo referido a una determinada intención. 

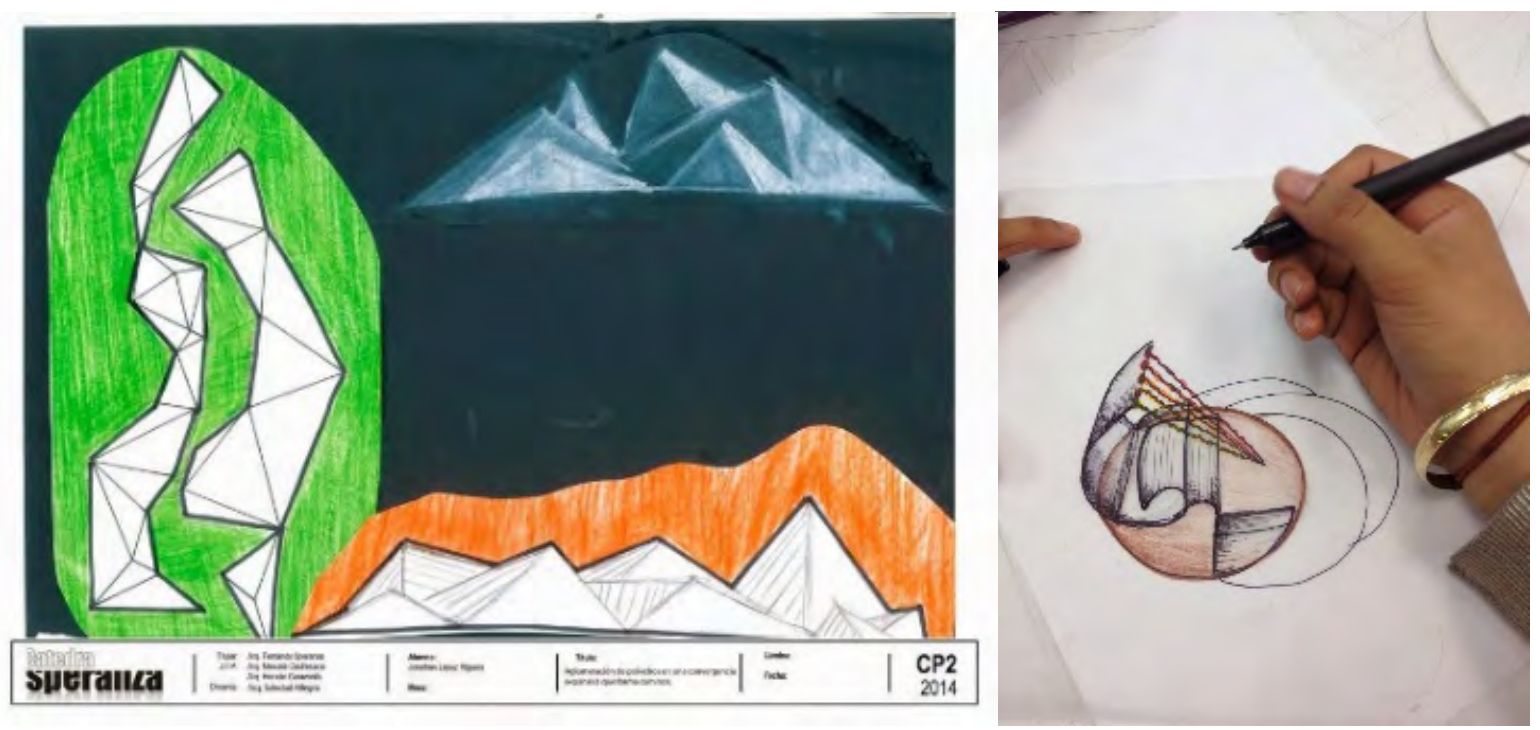

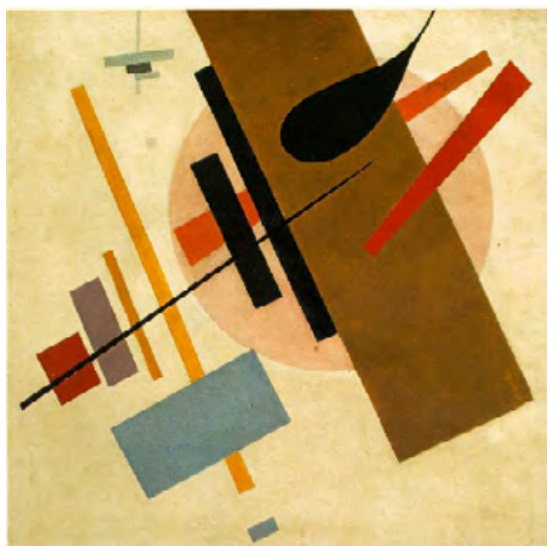

Figura 4. Una de las Pinturas estudiadas (Krusnoder, K. Malevich

1916) como punto de partida. Fuente: Grupo UN

Figuras 2 y 3. Imágenes iniciales previas al paso de su producción tridimensional.

Fuente: Grupo FADU

El grupo de la UN tomó un interesante camino en tanto los objetos se produjeron a manera de "móviles" lo que evitaba la aparición de una "base" así como la extrusión de la figura bidimensional de referencia.

¿Qué es un objeto - espacio / artefacto...? El problema tiene que ver con la definición inicial de un objeto sin escala, sin localización y sin un programa de uso fijado de antemano. El proceso de transformación parte así de interpretar su posible vocación. Asunto que debió ser hecho teniendo en cuenta su adaptación a un uso y una localización específica.
¿Cuáles son las diferentes instancias de interpretación? El ejercicio supone en primer término la interpretación de un lenguaje y una expresión plástica para ser llevado a la condición del objeto espacio. Luego surge el problema referido a la manera como es visto el objeto, así como a las herramientas con las que se puede analizar. Inicialmente se propone acudir a la mirada sintáctica, semántica y fenomenológica lo que permite entender el objeto como tal. Sin embargo, esto podría cambiar en el momento en que aparece el lugar de emplazamiento y con esto las relaciones intrínsecas se modifican necesariamente. 


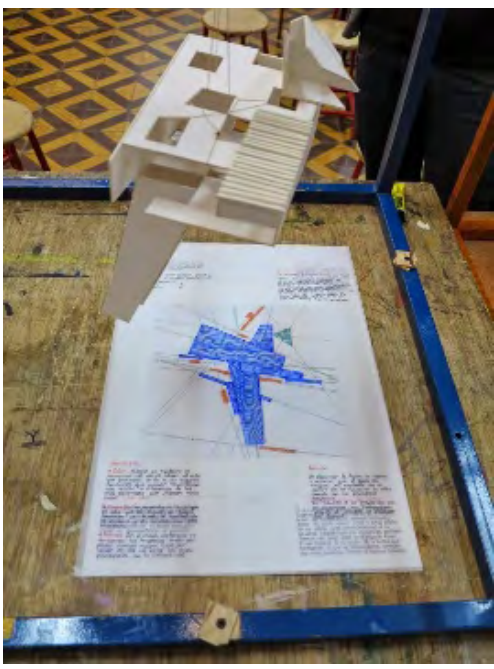

Figura 5. Una de las Pinturas estudiadas (Krusnoder, K. Malevich 1916) como punto de partida. Fuente: Grupo UN

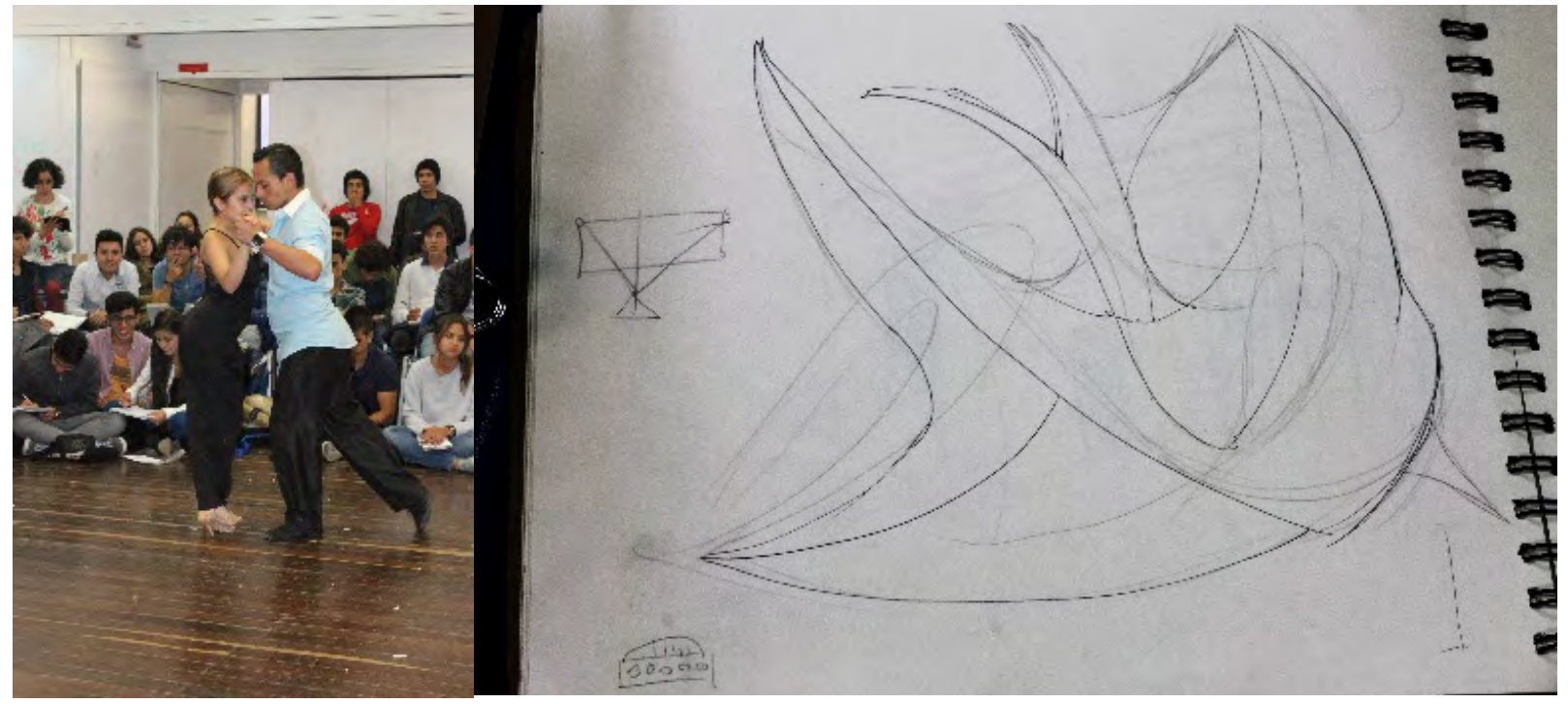

Figuras 6 y 7. Pareja de bailarines y regustro de su movimiento como punto de partida. Fuente: Grupo UA.
¿Es un problema de traducción? El ejercicio conlleva un proceso de traducciones que suceden en diferentes momentos y niveles. La idea general es traducida por los grupos docentes, los estudiantes a su vez también deben traducir el programa y las consignas. Luego, entre los emisarios y los receptores hay un diálogo que implica traducir las ideas de los objetos. Así, visto como problema general con aplicaciones particulares la traducción está presente como un fundamento del ejercicio.
¿Cómo es el proceso de representación - presentación? El problema de la representación y la presentación supone la necesidad de un formato y unas condiciones para su producción. No obstante conlleva la pregunta por los soportes adicionales: la denominación del objeto, el texto explicativo, las eventuales comunicaciones entre el productor y el receptor. Asuntos que se vinculan que a los modos de trabajo como el boceto, la maqueta, el CAD... etc. 
¿Cuáles son las formas y actitudes en el emplazamiento? La segunda parte del ejercicio supone el emplazamiento en un lugar existente y la asignación de un programa a partir de interpretar tanto las condiciones del objeto como las del lugar. En este sentido el abanico de posibilidades es muy amplio y permite pensar en diferentes actitudes que deriven de una necesaria argumentación.

¿Qué registrar y documentar? La tarea de registro, documentación y selección del material es parte fundamental del trabajo. Lejos de ser una tarea mecánica, supone un criterio que sin duda puede ser problematizado como formas de evaluación y auto-evaluación de las distintas instancias del ejercicio.

\section{Conclusiones}

A modo de cierre se podría decir que las tareas que conllevó el ws abren una serie de temas de interés para la enseñanza del proyecto en arquitectura así como en las demás áreas proyectuales.

1. El uso de las TICs debe ser entendido de manera integral. ${ }^{12}$ No se trata de contar con la tecnología como un medio para producir lo que históricamente se ha hecho de manera análoga. Es claro que el universo digital amplía el horizonte pedagógico y debe ser asumido tanto como un objetivo, un contenido y una instancia metodológica en el diseño curricular.

2. El trabajo colaborativo y la capacidad para la negociación entre pares de distintas procedencias es una condición del presente que debe ser potencializada en los procesos de diseño. Dice al respecto Alfredo Andia (2002): "Tradicionalmente la cultura arquitectónica ha basado su progreso en la capacidad creativa del diseño desde la figura del genio individual. Pero hoy, las condiciones urbanas y arquitectónicas presentan situaciones tan complejas que superan la capacidad individual". (2002).

3. Los aspectos pedagógicos que conlleva un ejercicio proyectual se mueven dentro de cuatro ejes simultáneos que juegan sus roles específicos sin que exista una correspondencia directa entre ellos, lo que explica la complejidad que suponen estos cursos y ejercicios introductorios. Deamer (2005) establece estos ejes en de los siguientes términos: 
Por un lado aparece el docente que actúa como crítico y su rol se basa en anteponer sus propios parámetros desde la experiencia y expectativas particulares. En este sentido opera a partir de una imagen de referencia y su anhelo es conseguirla. El programa por su parte es el documento en el que se establece el acuerdo, se fijan los parámetros operativos y se establecen condiciones. Asunto que tiene tras de sí una serie de aspectos ideológicos que por lo general no se hacen explícitos y que afectan el ejercicio de modo significativo. ${ }^{13}$ El objeto es el tercer aspecto, alrededor del cual gira la atención principal en tanto traduce y representa el discurso. Y por último el estudiante quien en el extremo opuesto debe producir y demostrar unas capacidades que como es sabido se evalúan dentro de un margen de relatividad.

Estos cuatro ejes simultáneos se ven afectados por el uso de las TICs en la medida que aportan

13 Entre los aspectos ideológicos se puede hacer mención del marco institucional de la escuela así como el "talante" del equipo docente. Dos aspectos que claramente superan las instrucciones contenidas en las guías. Prueba de esto es la diferencia en los resultados de un ejercicio entre un grupo y otro, pese a contar con un mismo guión. un espacio paralelo (virtual) que impone sus propias condiciones, permitiendo la sincronía, la diacronía y la comunicación en varios niveles. En este sentido se puede decir que pueden aportar a una mayor coordinación entre los cuatro ejes mencionados aunque también pueden ofrecer riesgos en la medida que dicho espacio virtual implica un modo de intercambio que no siempre es fácil de lograr.

4. Por último, vale la pena citar la pregunta que se hace Necdet Teymur (2011) a propósito de la necesidad de indagar en los procesos de aprendizaje en arquitectura: "¿Por qué investigar sobre la educación en arquitectura?" pregunta que podría extenderse a todas las áreas proyectuales del diseño; lo que sin duda incrementa su pertinenecia. Teymur basa su respuesta en la necesidad de adelantar investigación en este campo con el fin de estar a punto con las demandas cambiantes de la disciplina y la profesión y con esto evitar riesgos mayores. Asimismo, es necesario para hacer más complejo el conocimiento y enriquecerlo con otras disciplinas y nuevas miradas que trasciendan el ámbito particular. 
5. Queda abierta entonces la pregunta sobre las posibilidades que surgen de una experiencia como la descrita aquí, lo que posiblemente conduzca a la necesidad de pensar en aspectos de orden práctico como la operación de los cursos y los ejercicios mediante las TICs. Pero, al mismo tiempo, en asuntos pedagógicos en los que se asuma la tecnología como un medio que ofrece una gran capacidad en términos de la representación y la comunicación de las ideas.

\section{Referencias}

Andia, A. (2002). Internet Studios: Teaching Architectural Design On-Line between the United States and Latin America. Leonardo, 35, 3. $297-302$
Deamer, P. (2005). First Year: The Fictions of Studio Design. Perspecta, 36. Juxtapositions.

Lee, D. (1987). Integrating technology into the Architectural Curriculum. JAE. 41/7.

Speranza, F. (2014). Ficciones espaciales. Un estudio de caso en la didáctica del proyecto. Buenos Aires: Universidad de Buenos Aires.

Teymur, N. (2011). Aprender de la educación en Arquitectra. Dearq, No. 9, Educación en arquitectura. Universidad de los Andes, Bogotá.

Varnelis, K. (2007). Is there Research in the Studio. JAE. 61 (1).

Velandia, D. (2009). TIC's y los procesos de enseñanza-aprendizaje en arquitectura. Revista de-Arq 5. 166-175. 